\title{
SEQÜÊNCIA LATOSSOLO AMARELO - PODZÓLICO AMARELO - AREIAS QUARTZOSAS SOB MATERIAL DA FORMAÇÃO BARREIRAS NA REGIÃO DE TUCURỨ, ESTADO DO PARÁ
}

\author{
J.A.M. DEMATTÊ; R.R. ALOISI; J.L.I. DEMATTÊ \\ Departamento de Ciência do Solo, ESALQUSP - C.P., 9 - Cep: 13418-900 - Piracicaba,SP.
}

\begin{abstract}
RESUMO: Estudou-se uma sequência de Latossolo Amarelo-Podzolico Amarelo-Areia Quartzosa desenvolvida em sedimentos da Formação Barreiras. A área se localiza no sul do Pará, nas proximidades entre Tucurú e o Rio Moju, distando $65 \mathrm{~km}$ da Usina Ilidroelétrica de Tucuruí. Foi escolhida uma encosta de aproximadamente 1500 metros formada por Latossolo na parte alta e Podzolico Amarelo na encosta, ambos argilosos, terminando em amplo vale de fundo arenoso, com forte hidromorfismo. Os regimes de temperatura são isohipertérmico e hipertérmico e os de umidade ústico e áquico, nas partes elevadas e fundo do vale, respectivamente. Foram abertas quatro trincheiras ao Iongo da encosta e feitas oito tradagens para apoio. $O$ material de origem é representado pela caolinita. Verificouse que a diferenciação lateral dos solos: Latossolo Amarelo na parte alta, Podzolico Latoss6lico na encosta e Areia Quartzosa no fundo do vale, pode ser devida principalmente a processos de remoção e/ou destruição de finos (argila silicatada+ 6 xidos). 0 encharcamento temporánio e a gleização acentuada, exerceram papel preponderante na diferenciação da sequiência estudada.
\end{abstract}

Descritores: Sequência de solos, Latossolos Amarelos, Formação Barreiras, região de Tucurú.

\section{OXISOLULTISOLENTISOL SEQUENCE DEVELOPED FROM CLAYEY MATERIAI. NEAR TUCURUI REGION, PARÁ STATE, BRAZIL}

\begin{abstract}
The objective of this work was to study the genesis of an Oxisol-Ultisol-Entisol sequence, developed from sediments of the Barreiras Formation in the Tucurui region. The area is located about $65 \mathrm{~km}$ from Tucurui. In this area a soil toposequence was selected, represented by a clayey oxisol in the higher parts, a clayey ultisol in the middle part, ending in an ample valley of sandy botton, with strong hidromorphism. The temperature regimes are isohyperthermic and hyperthermic and the moisture regimes are udic and aquic, in the higher parts and valley botton, respectively. Four profiles were examined and auger samples were taken in eight representative sites. The parent material is represented by clayey sediments from the Barreiras Formation. Chemically, the soils are leached with high aluminum saturation, dominated by kaolinite clay minerals. In the higher parts of the sequence the textural gradient is similar and the iron oxides are mainly in crystalline forms. Downslope the textural gradient increases and the iron forms are less crystalline. At the valley botton the process of the fine fraction loss (also due to the hydromorphism) is completed remaining a sandy deep mantle. The iron oxides dissapear, remaining the kaolinite in smaller proportion. The soil sequence evolution may probably be developed by the degradation of the latossolic clayey material of the higher portions of the landscape.
\end{abstract}

Key Words: Soil sequence, Oxisol, Barreiras Formation, Tucuruí region.

\section{INTRODUÇÃO}

Os modelos clássicos de diferenciação de solos ao longo da encosta se apoiam principalmente na relação infiltração/ deflúvio, ilustrando aí a ação do relevo como fator de formação de solos (JENNY, 1941). Verticalmente os horizontes são formados por uma associação de processos específicos de gênese (SIMONSON, 1959) onde, no caso específico dos podzólicos, a translocação de argila tem um papel fundamental. MONIZ \& BUOL (1982) propuseram um modelo de desenvolvimento de horizontes mais estruturados ao longo da encosta, devendo-se isto a ação do fluxo lateral da água, tanto superficial como profundo. Neste caso a passagem lenta da água lateralmente vai comprimindo a massa do solo, reorientando as argilas dando a formação de agregados mais resistentes.

Nesta mesma época CHAUVEL (1981) e LUCAS et al. (1984) já propunham modelos mais complexos para o desenvolvimento de solos ao longo da encosta em áreas de Latossolos Amarelos, onde a desestabilização e perda da argila dos Latossolos se constituiam no processo dominante. 
Em relação a Amazônia, diversos trabalhos sobre gênese têm sido desenvolvidos, particularmente sobre estes solos: (CHAUVEL 1981 e CHAUVEL et al., 1982), especificamente sobre os mecanismos de gibbsitização e sobre a segregação de nódulos nos sedimentos da Formação Barreiras. LUCAS et al. (1984), estudando a transição Latossolos-Podzóis, também em material Formação Barreiras, verificaram que tais solos foram formados sobre o mesmo material e que a diferenciação entre eles se deve a desestabilização dos 6xidos de ferro. ANDRADE (1990) testou os mesmos princípios usados por LUCAS et al. (1984), para uma sequência de solos desenvolvidos do complexo guianense sobre rochas do tipo gnaisseo e granodiaritos.

Por ocasião do levantamento de solos do projeto de reflorestamento "Água Azul" localizado na região de Tucuruí, sul do Pará, notou-se que na região norte deste projeto $\varepsilon$ bastante comum ocorrência de relevos suave ondulados, ocupados pelo Latossolo Amarelo na parte alta e o Podzólico na encosta, ambos argilosos, transitando para vales constituídos de solos muito arenosos.

O objetivo é o de verificar se a sequência descrita por LUCAS et al. (1984) também se repete em outros pontos da Amazônia, ou seja, se a formação destes solos se deve a sedimentos diferenciados ou à pedogênese.

\section{CARACTERIZAÇÃo dO MEIO FísICO}

A área de estudo se localiza no sul do Pará, e está incluída na Folha SA.22 Belém do Projeto RADAMBRASIL mais precisamente entre os paralelos $3^{\circ} 00^{\prime}$ e $4^{\circ} 00^{\prime}$ e os meridianos $49^{\circ} 00^{\circ}$ e 4930' nas proximidades entre Tucuruí e Rio Moju. Tal área faz parte do Reflorestamento Água Azul de 30.000 ha e dista $65 \mathrm{~km}$ da Usina Hidroelétrica de Tucuruí.

O plano básico para o levantamento de solos dos primeiros 3.000 ha se apoiou numa malha de picadas abertas na mata, distanciadas de $1000 \mathrm{~m}$, designadas de Picada Norte-Sul e Picada EsteOeste. Para este trabalho, foi escolhida uma sequência de perfis de solos indo da parte alta da área próximo a Agrovila em direção ao Rio Cairari, tendo o Igarapé Aratéreo como divisor natural do lado leste (Figura 1).

Geologicamente a área está recoberta por material da Formação Barreiras. Indo em direção aos vales do rio Moju ou do Tocantins, ocorre material do Grupo Tocantins. Essa formação, apresenta uma excepcional variedade de tipos litológicos que variam de argilito a conglomerado (PROJETO RADAM, 1974). De maneira geral predominam arenitos finos $e$ siltitos, bem estratificados.

Como unidade morfo estrutural, a área de estudo faz parte da Depressão Periférica do Sul do Pará. Neste caso a dissecação fluvial do pediplano originou vales pouco encaixados em grandes áreas, dando relevos definidos como colinas de topo aplainado, onde observa-se a existência de "inselberg". A área de estudo em questão, é representada por um relevo plano a suave ondulado de interflúvios longos, ficando um pouco mais movimentado à medida que se dirige para os diversos igarapés. No Norte da área, ocorrem diversas depressões em forma de bacias fechadas, de drenagem impedida.

Os solos são predominantemente latossólicos, bastante dessaturados, argilosos a muito argilosos, distróficos ou álicos. Nas encostas, num relevo mais movimentado, sobre o mesmo material da Formação Barreiras tem ocorrido solos com uma estrutura no horizonte $B$ um pouco mais desenvolvida, de grau moderado, aparentemente Bt, sendo designado como Podzólico Amarelo, também distrófico ou álico. Nestas encostas há ocorrência esporádica de material laterítico. A textura do horizonte superficial passa de média para argilosa enquanto que no horizonte B a textura é argilosa a muito argilosa. Como já foi salientado, os fundos dos vales podem terminar em grandes depressões de forma de bacias irregulares, de drenagem pobre (Figura 1). Nestas áreas a textura do solo é arenosa.

Os regimes de umidade e de temperatura anuais são ústico $\mathrm{e}$ isohipertérmico para os Latossolos Amarelos (LA) e Podzólicos Amarelos (PA), áquico e hipertérmico no fundo do vale, respectivamente. A cobertura vegetal é caracterizada pela floresta Tropical Densa.

\section{MATERIAL E MÉTODOS}

Por ocasião do levantamento de solos da região do projeto "Reflorestamento Água Azul", observou-se que sobre um mesmo material da Formação Barreiras, e ao longo de encostas que terminam em vales em forma de bacias, ocorrem solos morfológicamente distintos, no caso o LA, $\mathrm{PA}$ e o Hi/Al, sendo os dois primeiros argilosos e - último arenoso. Foi escolhido assim, uma transeção (Figura 1), que representa justamente esta 
variabilidade de solos. Nesta região da transeção (Figura 2), foram abertas trincheiras para exame dos perfis de solos inclusive com amostragens dos horizontes. Ao mesmo tempo foram feitas tradagens de apoio ao longo das picadas, sendo 2 na Picada Norte $1\left(\mathrm{PN}_{1}\right), 3$ na $\mathrm{PN}_{2}, 4$ na $\mathrm{PN}_{3}$ e 3 na $\mathbf{P N}_{5}$.

Os perfis de solos foram designados de $P_{1}$ para o LA, $P_{2}$ e $P_{3}$ para o $P A$ e $P_{4}$ para o $\mathrm{Hi} / \mathrm{Al}$. As características morfologicas deste perfil permitiram enquadrá-lo preliminarmente na categoria das Areias Quartzosas hidromórficas. As tradagens foram designadas pela letra $T$. Os solos foram amostrados para as análises físicas, químicas e mineralógicas.

A análise granulométrica foi feita de acordo com o método de Vettori e Pierantoni (EMPRESA BRASILEIRA DE PESQUISA AGROPECUÁRIA, 1979), usando $\mathrm{NaOH}_{2} \mathrm{~N}$ como dispersante. $O$ ataque sulfúrico foi conduzido segundo o método descrito pela EMBRAPA (1979) utilizando o $\mathrm{H}_{2} \mathrm{SO}_{4} 1: 1$. O complexo sortivo também foi executado segundo EMBRAPA (1979). Cálcio, magnésio e alumínio trocáveis foram extraídos com $\mathrm{KCl} 1 \mathrm{~N}$. A extração do fósforo e do potássio foi feita com solução contendo $\mathrm{H}_{2} \mathrm{SO}_{4}$ $0,025 \mathrm{~N}+\mathrm{HCl} 0,050 \mathrm{~N}$. A extração do hidrogênio e do alumínio foi feita com acetato de cálcio $1 \mathrm{~N}$ a pH 7,0. O carbono foi determinado através da oxidação da matéria orgânica com bicromato de potássio. Os óxidos de ferro e de alumínio "livres" foram extraídos com citrato-bicarbonato-ditionito de sódio-CBD, (JACKSON, 1973). As formas menos cristalinas de 6 xidos de ferro e de alumínio foram extraidas com oxalato de amônio (MCKEAGUE \& RAY, 1966).

Análises mineralógicas para a fração silte e fração argila foram feitas com horizontes selecionados dos perfis de solos estudados. A metodologia utilizada para o preparo das amostras para difração dos raios X foi de JACKSON (1973). Ela consistiu no pré-tratamento para a eliminação da matéria orgânica e dos óxidos de ferro. Amostras da fração argila foram saturadas com $\mathrm{K}$ e com $\mathrm{Mg}$ e posteriormente transferidas orientadamente para lâminas de vidro (esfregaço) e posteriormente irradiadas num intervalo de 3 a 32 graus $2 \theta$ e as amostras de silte entre 3 e 62 graus 2 $\theta$. As amostras da fração silte foram moídas e analisadas pelo método do pó.

Amostras orientadas de horizontes da subsuperfície foram retiradas e preparadas para obtenção da secção delgada de acordo com método descrito por MENDES et al. (1973).

\section{RESULTADOS E DISCUSSÃO}

Os resultados aqui obtidos permitem inferências a respeito dos prováveis processos pedogenéticos envolvidos na encosta estudada. Sob material de origem heterogêneo, representado por sedimentos argilosos da Formação Barreiras, se instalou um intenso processo de intemperismo dando como produto uma massa latossólica. Na encosta estudada se distinguem 3 segmentos, a saber: as partes altas, que vai do topo ao terço superior da encosta, o final da encosta e o fundo do vale (Figura 2). O material latossólico parece ter ocupado os 3 segmentos da sequência, sofrendo posteriormente distintos processos pedogenéticos. Morfologicamente os solos bem drenados apresentam pequena variação de cor na seqüência, (TABELA 1) tendo na parte alta uma cor amarelo pardacento passando para oliva e oliva amarelado nos perfis 2 e 3 da encosta. Todos os perfis com exceção do $P_{4}$ são profundos $\mathrm{e}$ bem drenados apresentando entretanto, pequenos mosqueados, difusos pouco distinto de cor oliva disseminado em todo o perfil. Nos perfis 2 e 3 a concentração deste mosqueado difuso é maior no topo do horizonte B textural. Em profundidade, a massa do solo é latossólica, com horizonte $\mathrm{B}$ latossólico na posição de topo e sequência $\mathrm{Bt}$, $\mathrm{BW}$ nos perfis $\mathrm{P}_{2}$ e $\mathrm{P}_{3}$. A presença dos mosqueados difusos em todo o solo, tanto no $P_{1}$ como $P_{2}$ e $P_{3}$ permite a conclusão de que está ocorrendo um encharcamento temporário.

Nos perfis $\mathrm{P}_{2}$ e $\mathrm{P}_{3}$ há o desenvolvimento de estrutura em blocos de grau moderado com pequena evidência de cerosidade (TABELA 1). Entretanto, o exame micromorfológico dos horizontes $B$ destes perfis não indicou presença de cutãs iluviais. A ocorrência de fragmentos de laterita é comum na posição mais profunda destes perfis.

O desenvolvimento de horizonte mais estruturado nos perfis 2 e 3 deve estar mais relacionado ao fluxo lateral como comprovado por MONIZ \& BUOL (1982), e não à translocação de argila. A designação de um horizonte B textural neste caso, se deve mais ao gradiente textural como é aceito pelo sistema brasileiro de classificação de solos (CAMARGO et al., 1987).

O perfil 4 localizado no fundo do vale é de drenagem impedida praticamente acromático, no horizonte $\mathrm{C}$, onde a gleização é intensa. No horizonte $\mathrm{A} / \mathrm{C}$, de cor clara há pequenas pontuações de cor oliva $(2,5 Y 5 / 4)$, pouco distinto, um pouco mais argiloso do que a massa do horizonte como se fosse material remanescente da encosta. 
TABELA 1. Caracteristicas morfológicas dos perfis selecionados.

\begin{tabular}{|c|c|c|c|c|c|}
\hline \multirow{2}{*}{$\begin{array}{l}\text { Hori- } \\
\text { zonte }\end{array}$} & \multirow{2}{*}{$\begin{array}{l}\text { Profun- } \\
\text { didade }\end{array}$} & \multicolumn{2}{|r|}{ Úmida } & \multirow[t]{2}{*}{ Estrutura } & \multirow[t]{2}{*}{ Observações } \\
\hline & & Matriz & Mosqueado & & \\
\hline \multicolumn{6}{|c|}{ Latossolo Amarelo - P1 } \\
\hline $\begin{array}{l}\text { A1 } \\
\text { Bw1 }\end{array}$ & $\begin{array}{l}0-20 \\
20-60\end{array}$ & $\begin{array}{l}2,5 \text { YR } 5 / 4 \\
10 \text { YR } 5 / 6 \\
10 \text { YR } 6 / 6\end{array}$ & P,Df $(2,5 Y 5 / 1)$ & $\begin{array}{l}\text { B/G, P, Mo } \\
\text { B, P, F } \\
\text { Mac. Porosa }\end{array}$ & $\begin{array}{l}\text { Pontuações pequenas de matéria orgâ- } \\
\text { nica nos canais em todos os horizon- } \\
\text { tes. Os mosqueados são poucos difu- } \\
\text { sos e pequenos ao longo do perfil. In- } \\
\text { tensa atividade biológica. }\end{array}$ \\
\hline \multicolumn{6}{|c|}{ Podzólico Amarelo - P2 } \\
\hline $\begin{array}{l}\mathrm{Bt1} \\
\mathrm{Bw1}\end{array}$ & $\begin{array}{l}0-20 \\
20-50 \\
50-150\end{array}$ & $\begin{array}{l}2,5 \text { YR } 5 / 4 \\
10 \text { YR } 5 / 6 \\
7,5 \text { YR } 5 / 6\end{array}$ & $\begin{array}{l}\text { P,Df }(2,5 Y 5 / 1) \\
\text { P,Df }(2,5 Y 5 / 1)\end{array}$ & $\begin{array}{l}\text { B/G, P, Mo } \\
\text { B, M, Mo } \\
\text { B, P, F }\end{array}$ & $\begin{array}{l}\text { Pouca evidência de cerosidade. Os } \\
\text { mosqueados são poucos visíveis, pe- } \\
\text { quenos e irregulares, concentração de } \\
\text { matéria orgânica nos canais. }\end{array}$ \\
\hline \multicolumn{6}{|c|}{ Podzólico Amarelo - P3 } \\
\hline A1 & $0-25$ & 2,5 Y $5 / 4$ & & B/G, P, Mo & $\begin{array}{l}\text { Pouca evidência de cerosidade.Peque- } \\
\text { nas concentraçōes de matéria orgâni- }\end{array}$ \\
\hline Bw1 & $\begin{array}{l}25-80 \\
80-150\end{array}$ & 2,5 Y $5 / 6$ & C,Df (10YR 5/1) & $\begin{array}{c}\mathbf{B}, \mathbf{M}, \mathbf{M o} / \mathbf{F} \\
\text { B, P, F }\end{array}$ & $\begin{array}{l}\text { ca nos canais. Intensa atividade bioló- } \\
\text { gica. Os mosqueados são mais visíveis } \\
\text { principalmente no topo do B2. }\end{array}$ \\
\hline \multicolumn{6}{|c|}{ Areia Quartzosa Hidromórfico - P4 } \\
\hline Al & $0-15$ & $10 \mathrm{YR} 4 / 3$ & & $\mathbf{C}, \mathbf{P}, \mathbf{M F}$ & \\
\hline $\mathrm{A} / \mathrm{C}$ & $90-150$ & $10 \mathrm{YR} 5 / 4$ & C,M,Dt (10YR 6/6) & Maciça & $\begin{array}{l}\text { Poucas raízes. Pequena atividade } \\
\text { biológica. } \\
\text { Poucas raizes. Pequena atividade } \\
\text { biológica. }\end{array}$ \\
\hline
\end{tabular}

Mosqueado: $P=$ pouco; $D f=$ difuso; $C=$ comum; $D=$ distinto

Estrutura: $B / G=$ blocos/granular; $P=$ pequena; $M d=$ moderado; $F=$ forte; $M=$ média; Mac. $=$ maciça.

Exames micromorfologicos constataram serem pedorrelíquias, possivelmente material da mesma natureza dos segmentos da Formação Barreiras.

Quanto ao material de origem, verificouse que até a profundidade estudada ele é homogêneo, haja visto os dados da análise granulométrica (TABELA 2). A relação areia fina/areia grossa tem sido utilizada para estudos de homogeneidade nos materiais de origem do solo (VAN WAMBEKE, 1962; TYLER et al., 1975). Os valores desta relação tende a decrescer ligeiramente em profundidade e aumentando ligeiramente no sentido lateral. Este resultado indica que nesta encosta aparentemente não há descontinuidade litológica. A relação silte/argila apresenta valores inferiores a 0,3 , que de acordo com CAMARGO et al. (1987), indica solos muito intemperizados. Os valores dessa relação são ligeiramente mais elevados nas partes mais baixas (perfil $\mathbf{P}_{4}$ ). Neste caso, os valores mais elevados se devem a redução drástica nos teores de argila. A distribuição entre as relações de areia e silte sobre argila é bem semelhante, sugerindo que as pequenas variações em profundidade são mais devidas a diferenças dentro do material de origem do que as perdas ou ganhos relativos. 


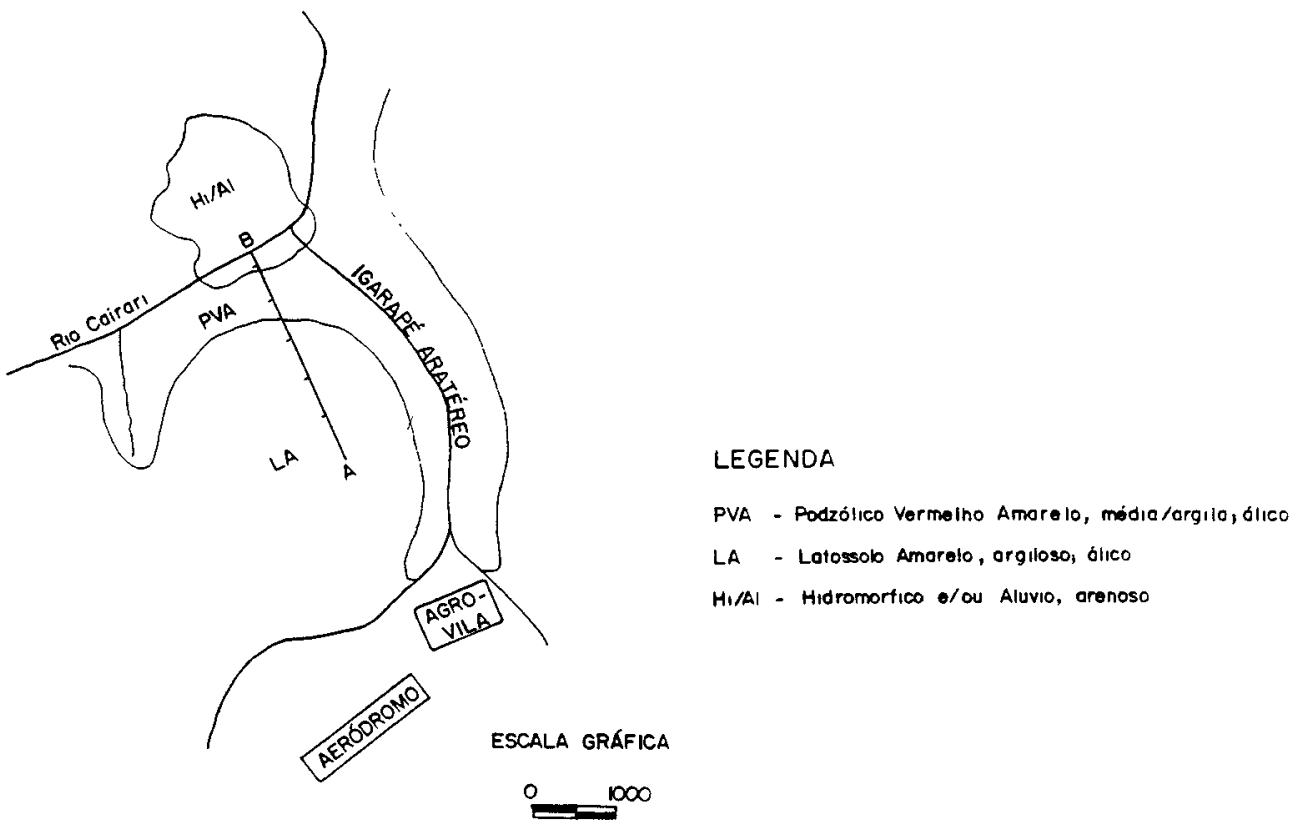

Figura 1. Esquema de distribuição dos solos próximos a AGROVILA do "Reflorestamento Água Azul" indicando a transeção $A B$ onde foi executado este trabalho.

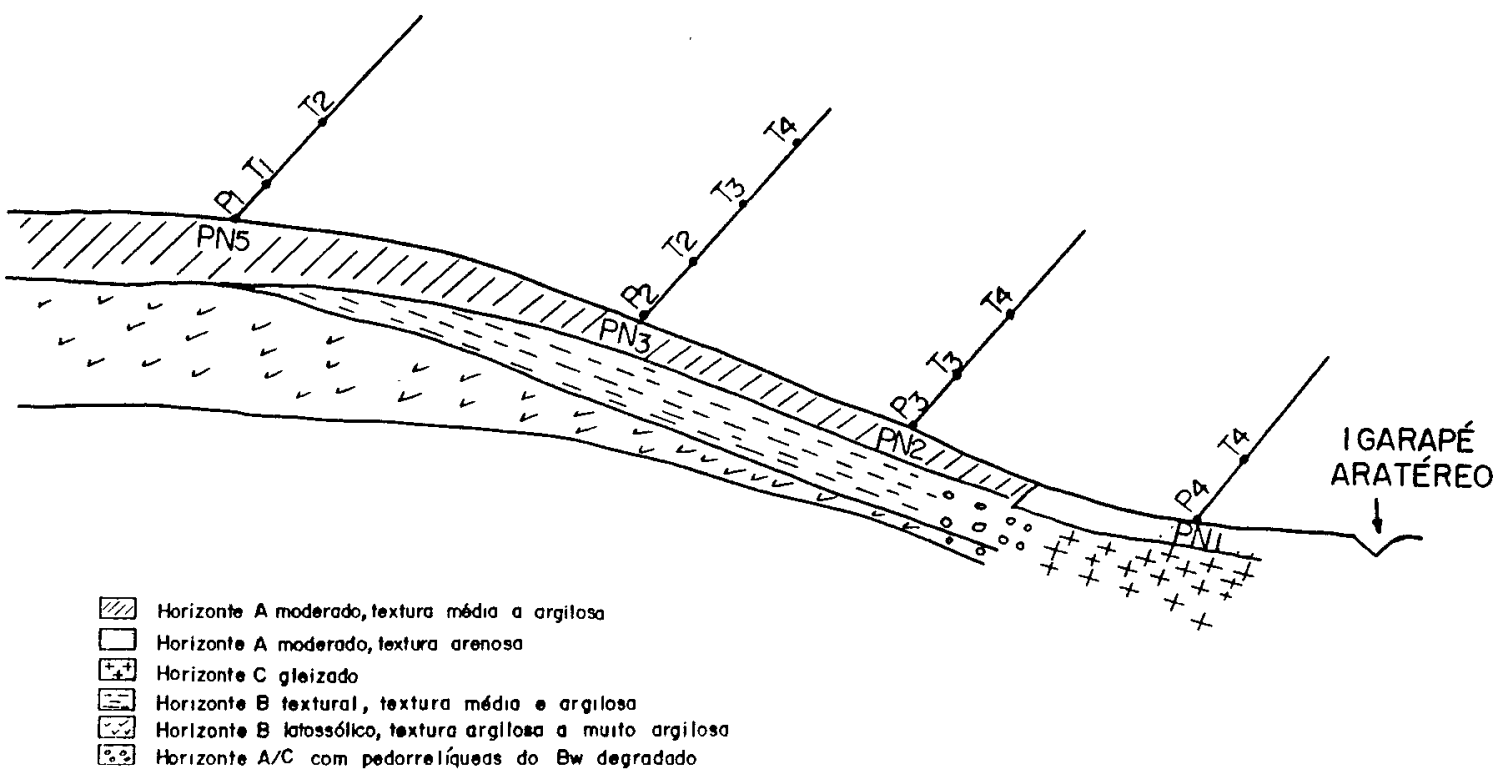

Figura 2 - Representação esquemática da transeção com os perfis examinados indicando a sequência de horizontes e o apoio das tradagens ao longo das picadas PN1, PN2, PN3 e PN5. PN=Picada Norte; $\mathrm{T} 1 . . \mathrm{T} 4=$ Tradagens; $P=$ Perfis

Sci. agric., Piracicaba, 51(2):345-356 maio/ago., 1994 
TABELA 2. Composição granulométrica, \% das unidades estudadas.

\begin{tabular}{|c|c|c|c|c|c|c|c|}
\hline \multirow{2}{*}{$\begin{array}{l}\text { Profun- } \\
\text { didade }\end{array}$} & \multirow[t]{2}{*}{ Horizonte } & \multicolumn{4}{|c|}{ Granulometria, \% } & \multirow{2}{*}{$\frac{\text { silte }}{\text { argila }} \times 100$} & \multirow{2}{*}{$\frac{\text { areia fina }}{\text { areia grossa }}$} \\
\hline & & $\begin{array}{c}\text { Areia } \\
\text { grossa }\end{array}$ & $\begin{array}{c}\text { Areia } \\
\text { fina }\end{array}$ & Silte & Argila & & \\
\hline \multicolumn{8}{|c|}{ Latossolo Amarelo (P1) PN 5} \\
\hline $0-20$ & A1 & 14 & 18 & 6 & 62 & 9,6 & 1,28 \\
\hline $20-60$ & Bw1 & 7 & 8 & 5 & 78 & 6,4 & 1,14 \\
\hline $60-150$ & $\mathrm{Bw} 2$ & 6 & 7 & 5 & 82 & 6,0 & 1,16 \\
\hline \multicolumn{8}{|c|}{ Latossolo Amarelo (T1) PN 5} \\
\hline $0-30$ & A1 & 16 & 19 & 6 & 59 & 10,1 & 1,18 \\
\hline $30-70$ & Bw1 & 11 & 16 & 6 & 67 & 8,9 & 1,45 \\
\hline $60-150$ & Bw2 & 7 & 8 & 5 & 78 & 6,4 & 1,14 \\
\hline \multicolumn{8}{|c|}{ Latossolo Amarelo (T2) PN 5} \\
\hline $0-25$ & A1 & 23 & 34 & 2 & 47 & 4,2 & 1,47 \\
\hline $25-60$ & Bw1 & 18 & 21 & 4 & 60 & 6,6 & 1,40 \\
\hline $60-150$ & Bw2 & 12 & 14 & 2 & 72 & 2,7 & 1,16 \\
\hline \multicolumn{8}{|c|}{ Podzólico Amarelo (P2) PN 3} \\
\hline $0-20$ & A1 & 21 & 21 & 11 & 47 & 23,4 & 1,00 \\
\hline $20-50$ & Bt1 & 10 & 12 & 2 & 75 & 2,6 & 1,20 \\
\hline $50-150$ & Bw2 & 7 & 10 & 1 & 83 & 1,2 & 1,42 \\
\hline \multicolumn{8}{|c|}{ Podzólico Amarelo (T2) PN 3} \\
\hline $0-25$ & Al & 21 & 26 & 9 & 44 & 20,4 & 1,23 \\
\hline $25-45$ & Bt1 & 14 & 16 & 6 & 64 & 9,3 & 1,14 \\
\hline $55-150$ & Bw2 & 8 & 8 & 6 & 78 & 7,6 & 1,00 \\
\hline \multicolumn{8}{|c|}{ Podzólico Amarelo (T3) PN 3} \\
\hline $0-18$ & Al & 28 & 30 & 10 & 32 & 31,2 & 1,07 \\
\hline $18-55$ & Bt1 & 21 & 22 & 7 & 50 & 14,0 & 1,04 \\
\hline $55-150$ & Bw2 & 14 & 16 & 1 & 69 & 1,4 & 1,14 \\
\hline \multicolumn{8}{|c|}{ Podzólico Amarelo (T4) PN 3} \\
\hline $0-30$ & Al & 23 & 28 & 12 & 37 & 32,4 & 1,21 \\
\hline $30-60$ & Bt1 & 17 & 21 & 7 & 55 & 12,7 & 1,23 \\
\hline $60-150$ & Bw2 & 13 & 14 & 3 & 70 & 4,2 & 1,07 \\
\hline
\end{tabular}




\begin{tabular}{|c|c|c|c|c|c|c|c|}
\hline \multicolumn{8}{|c|}{ Podzólico Amarelo (P3) PN 2} \\
\hline $0-25$ & A1 & 30 & 44 & 6 & 20 & 30,0 & 1,46 \\
\hline $25-80$ & Bul & 27 & 35 & 4 & 34 & 11,7 & 1,29 \\
\hline $80-150$ & Bw2 & 28 & 34 & 6 & 32 & 18,7 & 1,21 \\
\hline \multicolumn{8}{|c|}{ Podzólico Amarelo (T2) PN 2} \\
\hline $0-30$ & Al & 30 & 44 & 6 & 20 & 30,0 & 1,46 \\
\hline $30-80$ & Bt1 & 27 & 35 & 4 & 34 & 11,7 & 1,29 \\
\hline $80-150$ & Bw2 & 28 & 34 & 6 & 32 & 18,7 & 1,21 \\
\hline \multicolumn{8}{|c|}{ Podzólico Amarelo (T3) PN 2} \\
\hline $0-25$ & A1 & 26 & 47 & 1 & 26 & 3,8 & 1,80 \\
\hline $25-75$ & Bt1 & 24 & 35 & 9 & 32 & 28,1 & 1,45 \\
\hline $75-150$ & Bw2 & 24 & 33 & 1 & 42 & 2,3 & 1,37 \\
\hline \multicolumn{8}{|c|}{ Areia Quartzosa Hidromórfica (P4) PN 1} \\
\hline $0-15$ & A1 & 29 & 64 & 6 & 7 & 85,7 & 2,20 \\
\hline $15-90$ & $\mathbf{C l}$ & 31 & 60 & 1 & 8 & 12,5 & 1,93 \\
\hline $90-150$ & C2 & 31 & 61 & 1 & 7 & 14,2 & 1,93 \\
\hline \multicolumn{8}{|c|}{ Areia Quarzzosa Hidromórfica (T4) PN 1} \\
\hline $0-20$ & A1 & 35 & 54 & 3 & 8 & 37,5 & 1,54 \\
\hline $20-110$ & $\mathrm{Cl}$ & 35 & 43 & 3 & 15 & 20,0 & 1,10 \\
\hline $110-150$ & C2 & 37 & 47 & 1 & 15 & 6,6 & 1,27 \\
\hline
\end{tabular}

Quanto a textura, observa-se que o teor de argila decresce no sentido lateral e cresce no vertical (TABELA 2). A região alta é muito argilosa com teores de argila no Bw acima de $60 \%$ atingindo valor máximo de $82 \%$. Os resultados (TABELA 2) indicam que o teor de argila diminui progressivamente encosta abaixo, indo de $62 \%$ no topo para $26 \%$ no contato com o fundo do vale. Neste ponto o teor de argila atinge valores ao redor de 7\%. De acordo com o apoio bibliográfico utilizado, principalmente os trabalhos de CHAUVEL (1981) e ANDRADE (1984), associado com a aparente homogeneidade do material formador do solo até a profundidade estudada, incluindo aí a constatação de pedorrelíquias no $\mathrm{P}_{4}$ de natureza semelhante a massa formadora dos perfis 1 a 3 e fortalecido pela cristalinidade dos óxidos de ferro que se alteram gradativamente ao longo da encosta, inclusive no vale, supõe-se que todo o material formador destes solos seja único. Portanto, o principal processo pedogenético atuando sobre esta massa latossólica deve ter sido o da remoção de finos (argila e 6́xidos). Com a remoção gradativa da argila, há o aparecimento de um gradiente textural, máximo nas porções dos perfis $P_{2}$ e $P_{3}$, reduzindo-se nas porções inferiores. A remoção dos finos, através de processo de redução parcial ou total constatado pelas cores de redução em todos os perfis, é grande no final da encosta, tornando-se máxima no fundo do vale (Perfil $P_{4}$ ). Tal remoção parcial, no caso dos perfis $P_{2}$ e $P_{3}$ é muito acentuada no $P_{4}$, pode ter sido causado por um encharcamento temporário nas partes alta e encosta e um encharcamento permanente nas partes baixas, devido a presença do lençol freático, constatada através das descrições morfológicas (TABELA 1). Quimicamente (TABELA 3) são solos muito lixiviados, principalmente os perfis 
J.A.M. DEMATTÊ $e t$ al.

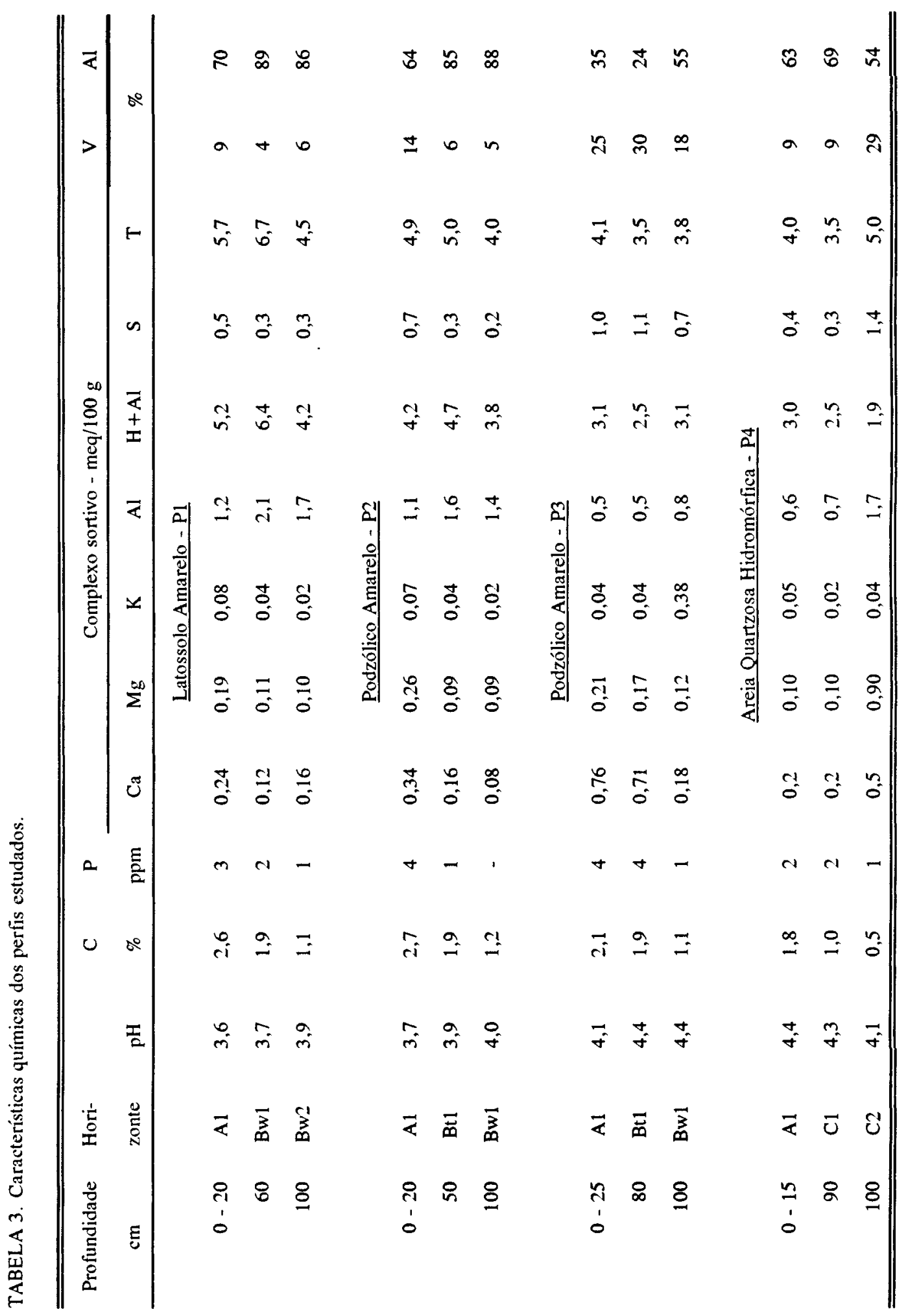


TABELA 4. Ataque sulfúrico e determinação dos óxidos nos perfis selecionados.

\begin{tabular}{|c|c|c|c|c|c|c|c|c|}
\hline \multirow[t]{2}{*}{ Horizonte } & \multicolumn{7}{|c|}{ Ataque Sulfúrico, \% } & \multirow[t]{2}{*}{$\mathrm{Ki}$} \\
\hline & $\mathrm{SiO}_{2}$ & $\mathrm{Al}_{2} \mathrm{O}_{3}$ & $\mathrm{Fe}_{2} \mathrm{O}_{3}$ & $\mathrm{TlO}_{3}$ & $\mathrm{MnO}$ & $\mathrm{P}_{2} \mathrm{O}_{5}$ & $\mathrm{~K}_{2} \mathrm{O}$ & \\
\hline \multicolumn{9}{|c|}{ Latossolo Amarelo - P1 } \\
\hline $\mathrm{A} 1$ & 22,8 & 18,4 & 8,8 & 1,3 & 0,02 & 0,03 & 0,04 & 2,1 \\
\hline Bw1 & 28,7 & 23,3 & 9,6 & 1,6 & 0,02 & 0,03 & 0,04 & 2,1 \\
\hline $\mathrm{Bw} 2$ & 30,8 & 26,1 & 12,1 & 1,8 & 0,02 & 0,02 & 0,04 & 2,0 \\
\hline \multicolumn{9}{|c|}{ Podzólico Amarelo - P2 } \\
\hline $\mathrm{A} 1$ & 12,1 & 9,1 & 3,0 & 0,5 & 0,01 & 0,00 & 0,01 & 2,3 \\
\hline Bt1 & 26,0 & 21,4 & 4,8 & 0,7 & 0,01 & 0,05 & 0,01 & 2,0 \\
\hline Bw1 & 28,0 & 25,0 & 6,0 & 0,9 & 0,01 & 0,01 & 0,01 & 2,0 \\
\hline \multicolumn{9}{|c|}{$\underline{\text { Podzólico Amarelo - P3 }}$} \\
\hline $\mathrm{A} 1$ & 8,0 & 5,8 & 1,2 & 0,5 & 0,01 & 0,00 & 0,01 & 2,4 \\
\hline Bt1 & 13,5 & 10,7 & 2,3 & 1,0 & 0,01 & 0,05 & 0,01 & 2,2 \\
\hline $\mathrm{Bw} 1$ & 14,3 & 11,9 & 3,4 & 1,0 & 0,01 & 0,01 & 0,01 & 2,1 \\
\hline \multicolumn{9}{|c|}{ Areia Quartzosa Hidromórfica - P4 } \\
\hline $\mathrm{A} 1$ & 10,1 & 6,1 & 1,6 & 0,9 & 0,01 & 0,01 & 0,01 & 2,8 \\
\hline $\mathrm{A} / \mathrm{C}$ & 12,0 & 9,8 & 1,0 & 0,7 & 0,04 & 0,01 & 0,01 & 2,2 \\
\hline $\mathrm{C} 1$ & 22,1 & 10,1 & 0,8 & 0,9 & 0,03 & 0,01 & 0,01 & 2,5 \\
\hline
\end{tabular}

localizados nas partes mais altas, com valores de saturação por bases inferiores a $10 \%$. A lixiviação é menos intensa no $\mathrm{P}_{3}$ devido a sua menor profundidade. Todos os perfis são álicos. O teor de carbono orgânico é mais elevado nos perfis mais argilosos, sendo mínimo no $\mathrm{P}_{4}$, de textura arenosa.

Mineralogicamente, os solos são caoliníticos (Figura 3a,b) e sendo que no silte há dominância de quartzo (Figura 3c), com Ki (TABELA 4) na faixa de 2,0 a 2,2 para os perfis 1 a 3 . No perfil 4 o Ki é ligeiramente superior a 2,0 ocorrendo alguns minerais 2:1 entre eles a vermiculita cloritizada.

Acompanhando a distribuição da fração argila, observa-se seqüência semelhante para os teores de ferro e de alumínio. Tais óxidos sofrem um decréscimo gradativo no sentido do topo para o fundo do vale (TABELA 4). Os dados da extração com CBD evidenciam uma distribuição semelhante àquela mostrada pelo ataque sulfúrico, ou seja, teores mais elevados de óxidos de ferro e de alumínio nas partes mais altas da encosta, reduzindo nas partes mais baixas (TABELA 5). Os resultados relacionados da extração com oxalato de amônia mostram valores inversos. A relação entre - ferro extraído pelo CBD e pelo oxalato de amônio indicam o grau de cristalinidade das argilas (BLUME \& SCHWERTMANN, 1969; JUO et al., 1974). Esta relação tende a decrescer em profundidade do perfil e aumentar ao longo da encosta. Sendo assim, o grau de cristalinidade aumenta com a profundidade do solo e diminui ao longo da seqüência. A medida que os óxidos vão ficando menos cristalinos, eles são mais facilmente removidos do solo ao se caminharem para as partes mais baixas, onde o hidromorfismo é máximo.

A razão de atividade entre os óxidos como foi salientado decresce em profundidade no solo, indicando que existe uma maior proporção de óxidos livres nas formas mais cristalinas na subsuperfície que na superfície do solo, devido a ação inibidora da matéria orgânica (McKEAGUE \& RAY, 1966). Por sua vez, os valores das relações entre os teores de ferro e a fração argila ao longo da sequêencia, não mostraram concentração relativa de ferro, significando que a translocação de argila nestes solos não é expressiva. No caso dos perfis 2 e 3 , o gradiente textural pode ser devido mais a remoção de finos do que à translocação de argila. A análise micromorfológica não evidenciou concentrações plasmáticas ao longo dos canais ou dos agregados. 
(a)

(b)
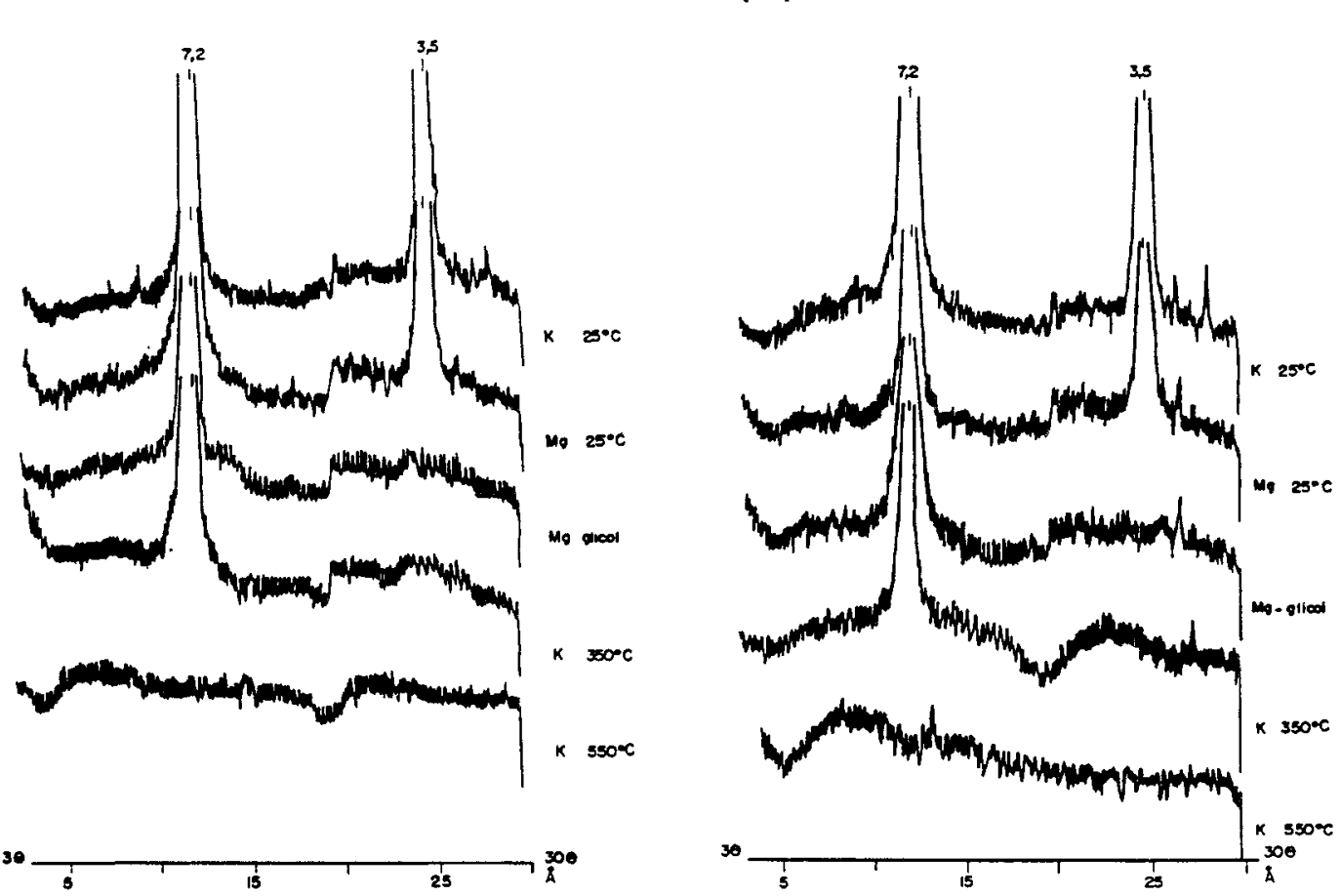

(c)
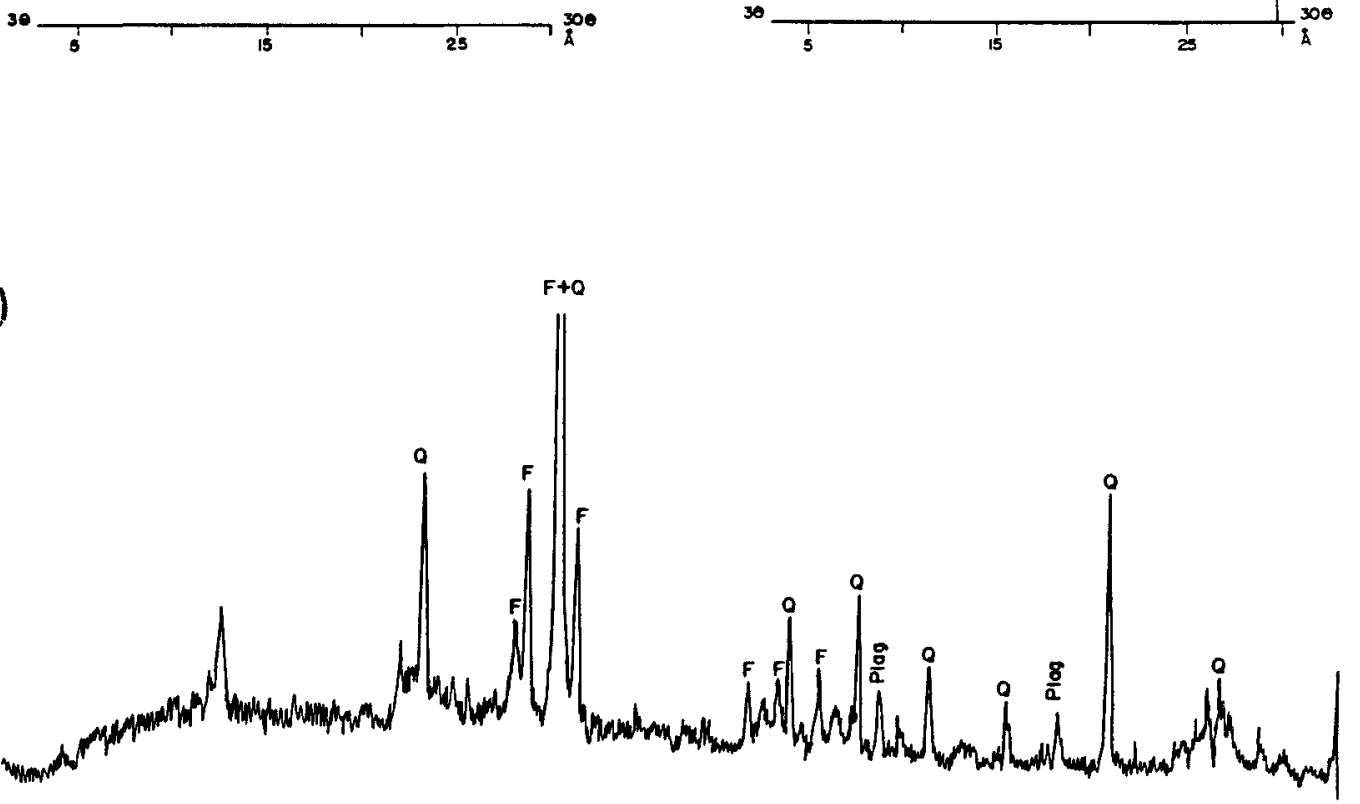

30

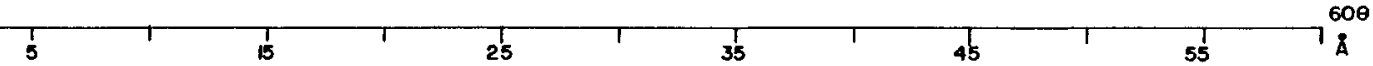

Figura 3 - Difração dos raios-X em amostras da fração argila sem ferro e saturadas com $\mathrm{K}$ e $\mathrm{Mg}$, do perfil 1, horizonte Bw (a); perfil 3, horizonte Bt (b) e em amostra de silte, sem ferro, perfil 2 , horizonte Bw (c).

Sci. agric., Piracicaba, 51(2):345-356 maio/ago., 1994 
TABELA 5 - Ferro e alumínio extraídos pelo Citrato-Bicarbonato-Ditionito e pelo Oxalato de Amônio dos perfis selecionados.

\begin{tabular}{|c|c|c|c|c|c|c|}
\hline \multirow[t]{2}{*}{ Horizonte } & \multicolumn{2}{|c|}{ Extração CBD } & \multicolumn{2}{|c|}{ Extração Oxalato Amônio } & \multirow{2}{*}{$\begin{array}{l}\text { Ferro ativo } \\
\times 1000\end{array}$} & \multirow{2}{*}{$\begin{array}{c}\text { Fe - CBD } \\
\text { argila }\end{array}$} \\
\hline & $\mathrm{Fe}_{2} \mathrm{O}_{3}$ & $\mathrm{Al}_{2} \mathrm{O}_{3}$ & $\mathrm{Fe}_{2} \mathrm{O}_{3}$ & $\mathrm{Al}_{2} \mathrm{O}_{3}$ & & \\
\hline \multicolumn{7}{|c|}{ Latossolo Amarelo - P1 } \\
\hline A1 & 8,0 & 3,2 & 0,8 & 1,6 & 1012 & 0,13 \\
\hline Bw1 & 8,7 & 3,0 & 0,5 & 1,7 & 574 & 0,11 \\
\hline $\mathrm{Bw} 2$ & 11,2 & 3,1 & 0,18 & 1,3 & 160 & 0,13 \\
\hline \multicolumn{7}{|c|}{ Podzólico Amarelo - P2 } \\
\hline Ap & 5,5 & 2,2 & 1,2 & 0,9 & 2181 & 0,11 \\
\hline Bt1 & 6,2 & 2,8 & 0,6 & 0,9 & 967 & 0,10 \\
\hline Bw1 & 6,0 & 1,7 & 0,3 & 1,1 & 500 & 0,08 \\
\hline \multicolumn{7}{|c|}{ Podzólico Amarelo - P3 } \\
\hline Ap & 4,1 & 1,5 & 1,1 & 1,5 & 2682 & 0,17 \\
\hline Bt1 & 4,7 & 1,4 & 0,99 & 0,9 & 2106 & 0,14 \\
\hline Bw1 & 4,0 & 1,5 & 0,48 & 1,0 & 1200 & 0,10 \\
\hline \multicolumn{7}{|c|}{ Areia Quartzosa Hidromórfica - P4 } \\
\hline Ap & 1,1 & 2,1 & 1,3 & 2,1 & 7277 & 0,25 \\
\hline $\mathrm{A} / \mathrm{C}$ & 2,0 & 1,4 & 1,5 & 1,8 & 7142 & 0,26 \\
\hline C1 & 1,8 & 0,6 & 1,3 & 1,3 & 7277 & 0,25 \\
\hline
\end{tabular}

Devido a essa remoção gradativa da fração argila, num manto presumivelmente latossólico se desenvolveram diversos solos, distribuídos na seguinte seqüência: Latossolos nas partes altas, Podzólicos Latossólicos nas partes inferiores da encosta $e$ Areias Quartzosas Hidromórficas no fundo do vale.

A remoção de argilas silicatadas e óxidos da superfície pode ser explicada por um processo parcial de redução associado à ação da matéria orgânica (TURENE, 1977; PEDRO, 1979). Tais compostos, podem migrar em profundidade ou se concentrar parcialmente na forma de material plíntico como ocorre no perfil 3. No caso de horizontes mais esbranquiçados como as partes inferiores do perfil 4, a perda da fração argila pode ser devida a processos mais intensos de destruição e remoção de finos, em função da alternância umectação-dessecação: a ferrólise segundo BRINKMAN (1970) e a acidólise, segundo MELFI \& PEDRO (1978).
Portanto, o resultado final leva a pensar que toda cobertura pedológica - Latossolos, Podzólicos Latossólico e Arejas Quartzosas, se desenvolveu sobre o mesmo material da Formação Barreiras. A diferenciação dos solos não seria devida a descontinuidades litológicas, mas a processos pedogenéticos de destruição e/ou remoção fração fina.

\section{CONCLUSÃO}

A diferenciação lateral dos solos: Latossolos na parte alta, Podzólico-Latossólico na encosta e Areia Quartzosa no fundo do vale, é devida princi-palmente a processos de remoção e/ou destruição de finos (argila silicatada + óxidos) do que a diferenças no material de origem. $O$ hidromorfismo exerce papel preponderante na diferenciação da sequiência estudada.

Mineralogicamente os solos são caoliníticos e quimicamente extremamente dessaturados. Em relação ao comportamento dos 
óxidos de ferro, verifica-se que o grau de cristalinidade decresce à medida que $o$ hidromorfismo se intensifica.

\section{REFERÊNCIAS BIBLIOGRÁFICAS}

ANDRADE, H. Evolução de uma sequiência de solos argilosos até arenosos no complexo guianense da Amazônia Ocidental. Piracicaba, 1990, 179p. Tese (Doutorado) - Escola Superior de Agricultura "Luiz de Queiroz", Universidade de São Paulo.

BLUME, H.P.; SCHWERTMANN, U. Genetic evaluation of profil distribution of aluminum, iron, and manganese oxides. Soil Science Society of America Proceedings, Madison, v.33, n.3, p.438-444, 1969.

BRINKMAN, R. Ferrolysis, a hydromorphic soil forming process. Geoderma, Amsterdam, v.3, n.3, p.199-206, 1970.

CAMARGO, M.N; KLAMT, E.; KAUFFMAN, J.H Classificação de solos usada em levantamentos pedológicos no Brasil. Boletim Informativo da Sociedade Brasileira de Ciência do Solo, Campinas, v.12, n.1, p.11-33, 1987

CHAUVEL, A. Contribuição para o estudo da evoluçãa dos latossolos amarelos, distróficos, argilosos na borda do Platô, na região de Manaus: mecanismos de gibbsitização. Acta Amazónica, Manaus, v.11, n.2, p.227-245, jun. 1981 .

CHAUVEL, A.; BOULET, R.; JOIN, P.; BOCQUIER, G. Aluminum and iron oxi-hydroxide segregation in nodules of Latossols developed on tertiary sediments (Barreiras Group) near Manaus (Amazon Basin), Brazil. In: INTERNATIONAL SEMINAR ON LATERISATION PROCESSES, 2, São Paulo, 1982. São Paulo: IAG/USP, 1982, p.507-526.

EMPRESA BRASILEIRA DE PESQUISA AGROPECUÁRIA. Serviço Nacional de Levantamento e Conservação de Solos. Manual de método de análise de solos. Rio de Janeiro, 1979.

JACKSON, M.L. Soil chemical analysis: Advanced course. Madison: Wisconsin University, 1973. 895p.

JENNY, H. Factors of soil formation. Macraw-Hill, New York, 1941, 285p.

JUO, A.R.S.; MOORMAN, F.R.; MADUAKOR, H.O. Forms and pedogenetic distribution of extractable $\mathrm{Fe}$ and $\mathrm{Al}$ in selected soils of Nigeria. Geoderma, Amsterdam, v.2, p.167-179, 1974.
LUCAS, Y.; CHAUVEL, A.; BOULET, R.; RANZANI, G.; SCATOLINI, F. Transição latossolos-podzóis sobre a formação barreiras na regiāo de Manaus, Amazônia. Revista Brasileira de Ciência do Solo, Campinas, v.8, n.3, p.325-335, Set/Dez, 1984.

McKEAGUE, J.A.; RAY, A. An evaluation of 0,1M pyrophosphate and pyrophosphate-dithionite in comparasion with oxalate as extractable of the accumulation products in podzol and some other soils. Canadian Journal of Soil Science, Ottawa, v.47, p. $95-99,1966$.

MENDES, A.C.T.; FALCI, S.C.; DEMATTÊ, J.L.I. Seçōes delgadas de solos: métodos de impregnação. Anais da Escola Superior Agricultura "Luiz de Queiroz", Piracicaba, v.30, p.35-48, 1973.

MELFI, A.J.; PEDRO, G. Considerações sobre os mecanismos geoquímicos envolvidos na alteração superficial e sua repartição no Brasil. Revista Brasileira de Genciências, São Paulo, v.8, p.11-22. 1978.

MONIZ, A.C.; BUOL, S.W. Formation of an OxisolUltisol transition in São Paulo, Brazil. I. Double layer water flow model of soil development. Soil Science Society of American Joumal, Madison, v.46, p.1228-1233, 1982.

PEDRO, G. Caracterization génerale des processus de l'alteration hydrolytique. Sciences du Sol., Versailles, n.2/3, p.93-105, 1979.

SIMONSON, R.W. Modern concepts of soil genesis. Soil Science Society of American Proceedings, Madison, v.23, p.152-156, 1959.

PROJETO RADAM. Folha SA.22. Belém. Rio de Janeiro: DNPM, 1974. 1v. (Levantamento de Recursos Naturais dos Solos, 5).

TURENE, J.F. Modes dhumification et differenciation podzolique dans deux toposéquences guyanaises. Memoire ORSTOM, Paris, n.84, 1977. 162p.

TYLER, E.J. Genesis of soils with a detailed soil survey in the upper Amazon basin. Yurimaguas, Peru. Raleigh, North Carolina State University, 1962. 171p. (Ph.D. Thesis).

VAN WANBEKE, A.R. Criteria for classifying tropical soils by age. Joumal of Soil Science, Edinburgh, v.13, p.124-132, 1962.

Enviado para publicação em 13.12.93

Aceito para publicação em 26.04 .94 